\title{
No evidence for developmental plasticity of color patterns in response to rearing substrate in pygmy grasshoppers
}

\author{
M. Karlsson, J. Johansson, S. Caesar, and A. Forsman
}

\begin{abstract}
Color polymorphisms in animals may result from genetic polymorphisms, developmental plasticity, or a combination where some phenotypic components are under strong genetic control and other aspects are influenced by developmental plasticity. Understanding how color polymorphisms evolve demands knowledge of how genetic and epigenetic environmental cues influence the development and phenotypic expression of organisms. Pygmy grasshoppers (Orthoptera, Tetrigidae) vary in color pattern within and among populations. Color morphs differ in morphology, behavior, and life history, suggesting that they represent alternative ecological strategies. Pygmy grasshoppers also show fire melanism, a rapid increase in the frequency of black and dark-colored phenotypes in populations inhabiting fire-ravaged areas. We examined the influence of plasticity on color polymorphism in the pygmy grasshopper Tetrix subulata (L., 1761) using a split-brood design. Individuals were experimentally raised in solitude on either crushed charcoal or white aquarium gravel. Our analyses uncovered no plasticity of either color pattern or overall darkness of coloration in response to rearing substrate. Instead, we find a strong resemblance between maternal and offspring color patterns. We conclude that pygmy grasshopper color morphs are strongly influenced by genetic cues or maternal effects, and that there is no evidence for developmental plasticity of coloration in response to rearing conditions in these insects.
\end{abstract}

Résumé : Le polymorphisme de la coloration chez les animaux peut résulter de polymorphismes génétiques, de plasticité au cours du développement ou d'une combinaison dans laquelle certaines composantes phénotypiques sont sous un fort contrôle génétique, alors que d'autres aspects sont influencés par la plasticité du développement. Une compréhension du développement des polymorphismes de la coloration exige une connaissance de l'influence des signaux environnementaux génétiques et épigénétiques sur le développement et l'expression phénotypique des organismes. Les tétrix (Orthoptera, Tetrigidae) ont des patrons de coloration qui varient au sein des populations et entre les populations. Les différents morphes de couleur diffèrent par leur morphologie, leur comportement et leur cycle biologique, indiquant qu'il s'agit de stratégies écologiques de rechange. Les tétrix possèdent aussi un mélanisme relié au feu, soit une augmentation rapide de la fréquence des phénotypes noirs et de couleur foncée dans les populations qui vivent dans des zones ravagées par le feu. Nous examinons l'influence de la plasticité sur le polymorphisme de la coloration chez des criquets granulés, Tetrix subulata (L., 1761), qui utilisent une stratégie de couvain divisé. Nous avons élevé expérimentalement des individus solitaires sur du charbon de bois écrasé ou sur du gravier blanc d'aquarium. Nos analyses ne décèlent aucune plasticité dans le patron de coloration, ni dans la noirceur globale de la coloration en réaction au substrat d'élevage. Nous observons plutôt une forte ressemblance entre les patrons de coloration de la mère et de ses petits. Nous en concluons que les morphes de couleur des tétrix sont fortement influencés par les signaux génétiques ou les effets maternels et qu'il n'existe aucune indication de plasticité de la coloration durant le développement en réaction aux conditions d'élevage chez ces insectes.

[Traduit par la Rédaction]

\section{Introduction}

Color and pattern may vary considerably among and within animal species (Poulton 1890; Cott 1940; Majerus 1998; Ruxton et al. 2004). One particularly striking example is color polymorphism, i.e., the occurrence of two or more discrete color variants within a population (Ford 1945; Rowell 1971). Such variation in color and pattern may be a direct reflection of variation among individuals in genetic cues in the form of allelic variation at polymorphic loci, or may reflect a plasticity of developmental processes in response to environmental conditions experienced during growth (Roff 1996; Pigliucci 2001; West-Eberhard 2003; Leimar 2005, 2009; Anstey et al. 2009). Differences in color and pattern among individuals may also reflect a combination whereby some components (such as patterning determined by the distribution of pigments) may be canalized and influenced by regulatory genes, and other components (such as the amount of pigments) may be influenced by structural genes and show an element of plasticity (Rowell

Received 23 February 2009. Accepted 12 August 2009. Published on the NRC Research Press Web site at cjz.nrc.ca on 6 November 2009.

M. Karlsson, J. Johansson, S. Caesar, and A. Forsman. ${ }^{1}$ School of Pure and Applied Natural Sciences, University of Kalmar, SE-391 82 Kalmar, Sweden.

${ }^{1}$ Corresponding author (e-mail: Anders.Forsman@hik.se). 
1971; Protas and Patel 2008). Information on the relative contribution of genes and how environmentally induced plasticity affects phenotypic variation is necessary for an increased understanding of the evolutionary dynamics of color polymorphisms. For example, if variation in color pattern among individuals largely reflects developmental plasticity in response to nongenetic environmental cues, then this may mask genetic variation and slow down the response to selection (Stearns 1989). It has also been argued that plasticity may facilitate the evolution of genetically determined color morphs by genetic assimilation (Waddington 1942; Pigliucci et al. 2006). Finally, the ability to adjust development and phenotypic attributes in response to environmental cues may also be considered an adaptation that provides a means for genotypes and populations to cope with changing conditions and selective regimes (Moran 1992; Pigliucci 2001; Miner et al. 2005).

Color polymorphism is common in Orthoptera and other insects (Rowell 1971; Dearn 1990). A green-brown polymorphism that seems to reflect plasticity in response to humidity or temperature experienced during development is common among certain acridoid grasshoppers (Rowell 1971). At the other end of the spectrum, the family Tetrigidae contains a number of highly color-polymorphic species where the polymorphism appears to be under strong genetic control and color and pattern are little influenced by plasticity in response to environmental conditions (Nabours 1929; Fisher 1930, 1939). Alternative color variants of Tetrix species are eco-morphs that differ not only in coloration but also in morphology, physiology, behavior, and life-history traits (Forsman 1999, 2000; Forsman and Appelqvist 1999; Forsman et al. 2002; Ahnesjö and Forsman 2003, 2006).

Although ample evidence suggests a genetic determination of the color polymorphism in tetrigids, it has recently been suggested that developmental plasticity in response to color of the substrate experienced during growth may contribute to the extreme variability in color and pattern seen in pygmy grasshoppers (Hochkirch et al. 2008), and it is theoretically possible that correlated plastic responses in different traits, so-called plasticity integration, may contribute to the associations of color and pattern with other traits (Pigliucci 2001). Developmental plasticity has also been invoked as an alternative explanation for fire melanism (i.e., the rapid increase in the relative frequencies of black (melanistic) and dark-colored phenotypes in populations living in recently fire-ravaged areas) in different species of insects (Hocking 1964; Rowell 1971; Majerus 1998), including pygmy grasshoppers (Karlsson et al. 2008).

Here we examine whether the extreme variability in color and pattern in the pygmy grasshopper Tetrix subulata (L., 1761) is influenced by developmental plasticity in response to environmental cues associated with burnt material. We reared offspring produced by females that belong to different color morphs in captivity in solitude using a split-brood design on two different substrates, crushed charcoal and white aquarium gravel, to address the following questions. (i) Do grasshoppers raised on charcoal substrate develop into color morphs different from those of their siblings raised on white aquarium gravel? Such a difference would be consistent with the hypothesis of environmentally induced developmental plasticity of color pattern elements.
We chose this design because not only the black color but also the chemical and physical properties of burnt material may serve as an environmental cue and induce a plastic response of color patterns. (ii) Do grasshoppers raised on charcoal substrate develop a color pattern that is darker overall compared with that of their siblings raised on white aquarium gravel? A darker appearance may reflect either a general darkening (e.g., via increased melanization of the entire animal) or an increase in the relative size of black and dark pattern elements at the expense of paler pattern elements. (iii) What is the relative contribution to the variation in color pattern among individuals of family (genes and maternal effects) and of developmental plasticity in response to the rearing substrate experienced during growth and development?

\section{Methods}

\section{Source population}

We collected 49 adult female $T$. subulata on 25 April and 9 May 2007 from a population inhabiting a large clear-cut area located in the vicinity of the village of Kosta, southcentral Sweden $\left(56^{\circ} 51^{\prime} 25^{\prime \prime} \mathrm{N}, 15^{\circ} 35^{\prime} 10^{\prime \prime} \mathrm{E}\right)$. The study site was burnt for management and conservation purposes in June 2003. Females were classified for color morph and housed individually (without access to males - they had mated prior to capture) for egg laying in the laboratory. We have previously shown that $T$. subulata are promiscuous and that neither males nor females show any mating preferences with regard to color morph (Caesar et al. 2007). More detailed information on the source population and collection procedure as well as descriptions and photographs of the alternative color morphs are provided in Karlsson et al. (2008).

\section{Color morphs}

Tetrigid grasshoppers display a remarkable variation in color and pattern of the pronotum, legs, and other parts of the body (Karlsson et al. 2008). Ground colors are black, light grey, dark brown, pale brown, reddish brown, yellowish brown, and olive green. Some morphs are monochrome but others have pattern elements consisting of longitudinal stripes of several widths and colors along the median pronotum or on the femora of the jumping legs, or specks or spots about the middle or periphery of the pronotum or on the jumping legs. Morphs also vary with regard to texture of the integument on the pronotum and the femora of the jumping legs, the surface being either smooth, or granular and rough, or consisting of longitudinal ridges and grooves (veining). Some variation exists also within color morphs. For instance, individuals may or may not have distinct white markings on the femora of the jumping legs. Furthermore, individuals may appear greenish or olive, and appear to gradually turn darker and change color over time because they become covered with growth of algae (Helfer 1987).

\section{Captive rearing}

Female T. subulata were maintained in the laboratory for egg laying at $28 \pm 1{ }^{\circ} \mathrm{C}, 75 \%$ relative humidity, and a $12 \mathrm{~h}$ light : $12 \mathrm{~h}$ dark cycle. Four fluorescent strip lights (Philips Master TL 28W/830 HE) mounted in the ceiling were used 
as a complement to the natural light. A.F. classified each of the females according to color morph before placing them individually in plastic cups (Cerbo model A380, height $95 \mathrm{~mm}$, bottom diameter $64 \mathrm{~mm}$, and top diameter $90 \mathrm{~mm}$ ) for egg laying. A circular opening (50 mm diameter) was cut in the bottom of each cup and covered with a plastic mesh $(1.5 \mathrm{~mm} \times 1.5 \mathrm{~mm}$ grid). The top of each plastic cup was covered with fibercloth (Weibulls) kept in place by a lid in which a $72 \mathrm{~mm}$ diameter circular opening had been cut. The cups were placed on trays with a damp moistureretaining cloth and covered with plastic film to maintain humidity. Each cup was supplied with a small aluminum container $(25 \mathrm{~mm}$ diameter) filled with a 1:1 mixture of moist peat and soil as oviposition medium (Forsman et al. 2002). Egg pods were incubated on a piece of moist cotton inside a plastic petri dish (80 $\mathrm{mm}$ diameter) under the same temperature conditions as where they had been laid. We inspected egg pods for hatchlings on a daily basis and released newly hatched nymphs in their outdoors rearing cups (see below).

\section{Split-brood experimental design}

We used a split-brood design to investigate whether color patterns of pygmy grasshoppers are influenced by the substrate material experienced during growth and development. Newly hatched nymphs $(N=496)$ were reared individually in plastic cups (described above) filled to $1 / 5$ volume with a 1:1 mixture of peat and soil, and five straws of Polytrichum sp. moss for food, cover, and climbing opportunities. In half of the cups $(N=245)$ we added a layer of finely crushed charcoal and in the other half $(N=251)$, a layer of white aquarium gravel. We chose this design because not only the black color but also the chemical and physical properties of burnt material may serve as an environmental cue and induce a plastic response of color patterns. Cups were arranged in plastic racks to prevent them from tipping over, placed out of doors exposed to natural sunlight, and covered with wire mesh to exclude predation by birds. Water was provided by an automatic sprinkler system (Hozelock AC1 simple water computer: 2705 automatic timer coupled to two Hozelock AquaStorm 2'n1 XL: 2977 sprinklers) set such that the cups were watered for $5 \mathrm{~min}$ in the morning and afternoon every day.

Temperature conditions inside the rearing cups may affect the physiology and behavior of the grasshoppers and influence the growth of algae and moss used as food by grasshoppers during the experiment. We therefore recorded weather conditions (clear sky, cloudy, or rain) and sun exposure (i.e., whether the cups were exposed to direct sunlight or shade) and monitored the temperature with max-min digital thermometers inside four pairs of cups (one pair in each corner of the grid) filled with either charcoal or white aquarium gravel. Results from a general linear model analysis revealed that temperature inside the rearing cups was influenced by weather conditions $\left(F_{[3,183]}=50.56, P<0.05\right)$ but not by substrate treatment $\left(F_{[1,183]}=1.92, P=0.17\right)$, position in the grid $\left(F_{[3,183]}=0.91, P=0.44\right)$, or the interaction of weather and substrate treatment $\left(F_{[3,183]}=0.43, P=\right.$ 0.74). When the interaction between weather and substrate treatment was removed from the model, the effect of weather remained significant (effect of weather: $F_{[3,186]}=$
50.68, $P<0.05$; position: $F_{[3,186]}=0.94, P=0.92$; substrate: $\left.F_{[1,186]}=2.9, P=0.09\right)$.

Tests of phenotypic plasticity of color patterns may be confounded by differences in light conditions between different measurement occasions, as well as by inter- and intra-observer differences in the assignment of color patterns. We took several precautions to minimize and assess the potential influence of such biases in our study. To avoid interobserver biases, the color morph of all individuals was scored by the same person (A.F.). To minimize any effects of intra-observer inconsistencies, we photographed the animals and scored color pattern and estimated overall darkness from digital images. To avoid inter-observer biases in estimates of overall darkness, this variable was scored from digital images by the same person (J.J.). To assess the influence of intra-observer inconsistencies, we estimated measurement error of color morph assignment and of the overall darkness of color patterns.

\section{Photographing study animals and scoring of color patterns}

We surveyed the experimental animals on two occasions, 3-5 June 2007 and 28-30 July 2007. On each occasion we recorded the number of live grasshoppers and A.F. scored them for color pattern. On the second inventory we also photographed the grasshoppers individually from above to obtain a dorsal view of the pronotum and enable subsequent, more careful analysis of color patterns using image analysis. We held the grasshopper by hand such that it rested on a pin nailed through the bottom of a plastic cup covered with light brown paper. This ensured that the distance from the lens to the grasshopper was kept constant $(227 \mathrm{~mm})$ between individuals. We used a Canon EOS 30D camera, a Canon EF 100/2.8 macro USM lens, and a Sigma EM-140 DG Macro flash. Camera settings were ISO 200, aperture 11, partial light metering, light temperature $5600 \mathrm{~K}$, and shutter speed 1/250 s. We used Adobe Photoshop CS3 to view the digital images and analyze grasshopper color patterns, as described below.

\section{Using image analysis to quantify color patterns and estimate measurement repeatability}

To avoid inter-observer biases and estimate measurement repeatability of our color morph data, A.F. scored the color morph of all individuals based on the digital images showing the dorsal view of the pronotum on two separate occasions. The second scoring was performed blind with regard to the results of the first scoring. Individuals were classified as belonging to one of the following morphs: monochrome black, striped, dark brown, brown, black with yellowish markings above front legs, mottled brown, mottled black, striated, mottled dark brown, mottled pale brown, pale brown, latte, mottled, and rusty red. As an estimate of measurement repeatability, we calculated the percentage of individuals that were classified as belonging to the same color morph in the two separate scoring sessions. We found that $93 \%$ (125 of 135) of adults and 86\% (119 of 139) of nymphs were classified as belonging to the same color morph on both occasions.

We quantified overall darkness of the color pattern by opening the images with Adobe Photoshop CS3. We se- 
lected a rectangular area (on average, 118 pixels $\times 117$ pixels) that covered a large portion of the widest part of the pronotum from the posterior angle to the posterior end of the elytra, and used the mean RGB value option, which measures the average darkness of color for the red, green, and blue channels from 0 (black) to 255 (white). To ensure that the RGB values obtained from analysis of digital images reliably reflected overall darkness, we photographed Swedish Natural Color System (NCS) standards under the same conditions as the grasshoppers and analyzed the digital images. We explored the relationship between the darkness of the image as indicated by the NCS darkness value, from 0 (white) to 100 (black), and as estimated using Photoshop mean RGB values. Analyses of data for 15 different NCS standards revealed that mean RGB values from digital images in Photoshop reliably reflect the overall darkness of colors (as evidenced by the least squares linear regression of RGB against NCS darkness: RGB $=153.4-1.07 \times$ NCS darkness, $\left.R^{2}=0.85, F_{[1,13]}=8.62, P<0.0001\right)$.

To estimate measurement repeatability of our estimates of overall darkness of color pattern, we photographed 23 individuals on two separate occasions on the same day and analyzed the data with one-way ANOVA with individual identity as the fixed factor. Repeatability was computed as $S_{\mathrm{B}}^{2} /\left(S_{\mathrm{B}}^{2}+S_{\mathrm{W}}^{2}\right) \times 100$, where $S_{\mathrm{B}}^{2}=\left(\mathrm{MS}_{\mathrm{B}}-\mathrm{MS}_{\mathrm{W}}\right) / k, S_{\mathrm{W}}^{2}=$ $\mathrm{MS}_{\mathrm{W}}, k$ is the number of measurements per individual, and $\mathrm{MS}_{\mathrm{W}}$ and $\mathrm{MS}_{\mathrm{B}}$ are the mean squares obtained within and between individuals, respectively (Sokal and Rohlf 1981). We arrived at a repeatability estimate of $96 \%\left(F_{[22,23]}=43.27\right.$, $P<0.0001)$ for overall darkness of the dorsal color pattern, i.e., only $4 \%$ of the variation in dorsal darkness among individuals was due to measurement error.

\section{Statistical analyses}

\section{Testing for effects of rearing substrate on survival}

A difference (if present) in the distribution of color morphs between rearing substrates at the termination of the experiment could reflect differential survival of alternative morphs reared on different substrates, rather than plasticity of color pattern development. We therefore tested for independence of survival from first to second census on rearing substrate (black charcoal or white gravel) and color morph at first census using pairwise contingency table analyses.

\section{Testing for independence of color morph on maternal identity and rearing substrate}

To assess the relative contribution to the observed variation in color pattern among individuals of family (genes and maternal effects) and of rearing substrate experienced during growth and development, we used data from the second census and tested for independence among color morph (treated as a categorical variable), rearing substrate (black charcoal or white gravel), and maternal identity using log-linear analysis (Bishop et al. 1974; Sokal and Rohlf 1981) implemented using the CATMOD subroutine in SAS (SAS Institute Inc. 2004). Tests of independence were based on comparisons of fit between a model including and a model lacking the interaction of interest using a log-likelihood ratio statistic. In this approach, dependence of color pattern on the substrate experienced during development would be manifest as a significant interaction between color morph and rearing substrate.

\section{Testing for effects on overall darkness of maternal identity and rearing substrate}

To test for effects on overall darkness of color pattern of individuals of $(i)$ their own color morph, (ii) rearing substrate treatment (black charcoal or white gravel) experienced during growth and development, and (iii) family (genes and maternal effects), we analyzed data on RGB value from the second census using ANOVA. To evaluate the possibility that overall darkness of different color morphs may respond differently to rearing substrate, we included in the model each individual's own color morph by rearing substrate interaction as an independent explanatory variable. We also tested for an effect of rearing substrate on overall darkness using a mixed model approach by treating rearing substrate as a fixed effect and family as a random effect, implemented with the MIXED subroutine in SAS and using the maximum-likelihood estimation method.

Not all individuals had eclosed into the adult form at the termination of the experiment shortly before the onset of winter inactivity. We first analyzed our data for nymphs and adults together to obtain large sample sizes and high statistical power. We then repeated the analyses on a restricted data set that contained data for mature individuals only, to avoid confounding effects of differences in developmental stage and ontogenetic change that may be mistakenly interpreted as phenotypic plasticity. Finally, we performed a matched paired comparison of overall darkness by restricting the data set to pairs of siblings in which both individuals belonged to the same color morph but had been raised on different substrates. Different pairs represented different color morphs.

\section{Results}

We used 496 newly hatched nymphs, representing offspring from 49 different mothers, and placed them individually in separate plastic cups with either black charcoal $(N=$ $245)$ or white aquarium gravel $(N=251)$. The majority of released nymphs, $70 \%$ (346 of 496), were still alive at the time of the second census at the end of July when the experiment was terminated. Survival from release to second census was independent of whether individuals had been raised in cups with white (169 of 251) or black (177 of 245) substrate $\left(\chi_{[1]}^{2}\right.$ adjusted for continuity $=1.19, P=$ 0.27 , Fisher's exact $P=0.24$ ). Survival from first to second census was also independent of color morph as determined at the first census $\left(\chi_{[9]}^{2}=7.42, P=0.59\right)$. These results suggest that differential mortality of alternative morphs reared on different substrates is unlikely to have confounded our tests for effects of rearing substrate on color pattern and overall darkness, reported below.

\section{Color pattern depended on maternal color morph but not on rearing substrate}

\section{Results based on analyses of data for all individuals and for adults only}

The distribution of the 346 individuals that were alive at the termination of the experiment among the 14 different 
color morphs was highly dependent on maternal color morph (log-linear model analysis, effect of own morph by maternal color morph interaction: $G=93.50$, df $=58, P=$ 0.0022 ) but independent of whether rearing cups contained black or white substrate (effect of own morph by rearing substrate interaction: $G=10.12$, df $=11, P=0.52$ ). The three-way own morph by maternal morph by rearing substrate interaction was nonsignificant $(P>0.9)$, which does not support a role of gene by rearing environment (of developing nymphs) interaction effects for the phenotypic expression of color morph. We concluded that the distribution of individuals among different color morphs was independent of rearing substrate also when we restricted the analyses to data for the 156 individuals that had reached the adult stage (i.e., such that we could determine their color morph with higher accuracy) at the termination of the experiment (effect of own morph by substrate interaction: $G=5.63$, $\mathrm{df}=9, P=$ 0.77) (Fig. 1).

\section{Overall darkness depended on family and own color pattern but not on rearing substrate}

\section{Results based on analyses of data for all individuals and for adults only}

The overall darkness of the dorsal surface of individuals varied among families and among individuals that belonged to different color morphs, but was not influenced by whether individuals had been raised on crushed charcoal or white aquarium gravel (Table 1). There also was no heterogeneity among color morphs in their (lack of) response to rearing substrate (as evidenced by the nonsignificant morph by rearing substrate interaction, Table 1). Results were qualitatively similar when we analyzed nymphs and adults together and adults only.

We concluded that rearing substrate did not influence overall darkness of individuals also when we analyzed data using the mixed model approach, regarding family as a random effect and rearing substrate as a fixed effect (effect of rearing substrate, result from analysis of pooled data for nymphs and adults: $F_{[1,41]}=2.41, P=0.13$; data for adults only: $\left.F_{[1,25]}=2.29, P=0.14\right)$.

\section{Results based on matched paired comparisons within families and color morphs}

The analysis of our restricted data set for 35 pairs of individuals matched with regard to color morph (pairs representing 26 families) also uncovered no effect of rearing substrate. The mean difference in overall darkness between siblings reared on crushed charcoal versus white aquarium gravel did not differ from zero (mean difference $=1.80$, $95 \%$ confidence interval -4.10 to 0.20 ) (Fig. 2).

\section{Discussion}

Differences in colors and patterns among individuals and populations may reflect underlying differences in coding and regulatory genes or developmental plasticity and differential expression of genotypes in response to environmental conditions experienced during growth (Protas and Patel 2008). Information on the relative contribution of genes and how environmentally induced plasticity affects phenotypic variation is necessary for an increased understanding of the evo-
Fig. 1. Relative color morph frequencies among pygmy grasshopper (Tetrix subulata) individuals experimentally reared from the hatchling stage on crushed charcoal (top panel) or white aquarium gravel (bottom panel) using a split-brood design. Comparison is restricted to data for the 156 (of 346) individuals that had reached the adult stage at the termination of the experiment. Numbers below horizontal axes represent color morphs: 1, monochrome black; 2 , striped; 3, dark brown; 4, brown; 5, black with yellowish markings above front legs; 6, mottled brown; 7, mottled black; 8, striated; 9, mottled dark brown; 10, mottled pale brown; 11, pale brown; 12, latte; 13 , mottled. Color morph was treated as a categorical variable in the statistical analysis; numbers in the legend are only for identification. The distribution of individuals among color morphs is independent of rearing substrate (log-linear model analysis, effect of own morph by rearing substrate interaction, $P=0.77$ ).

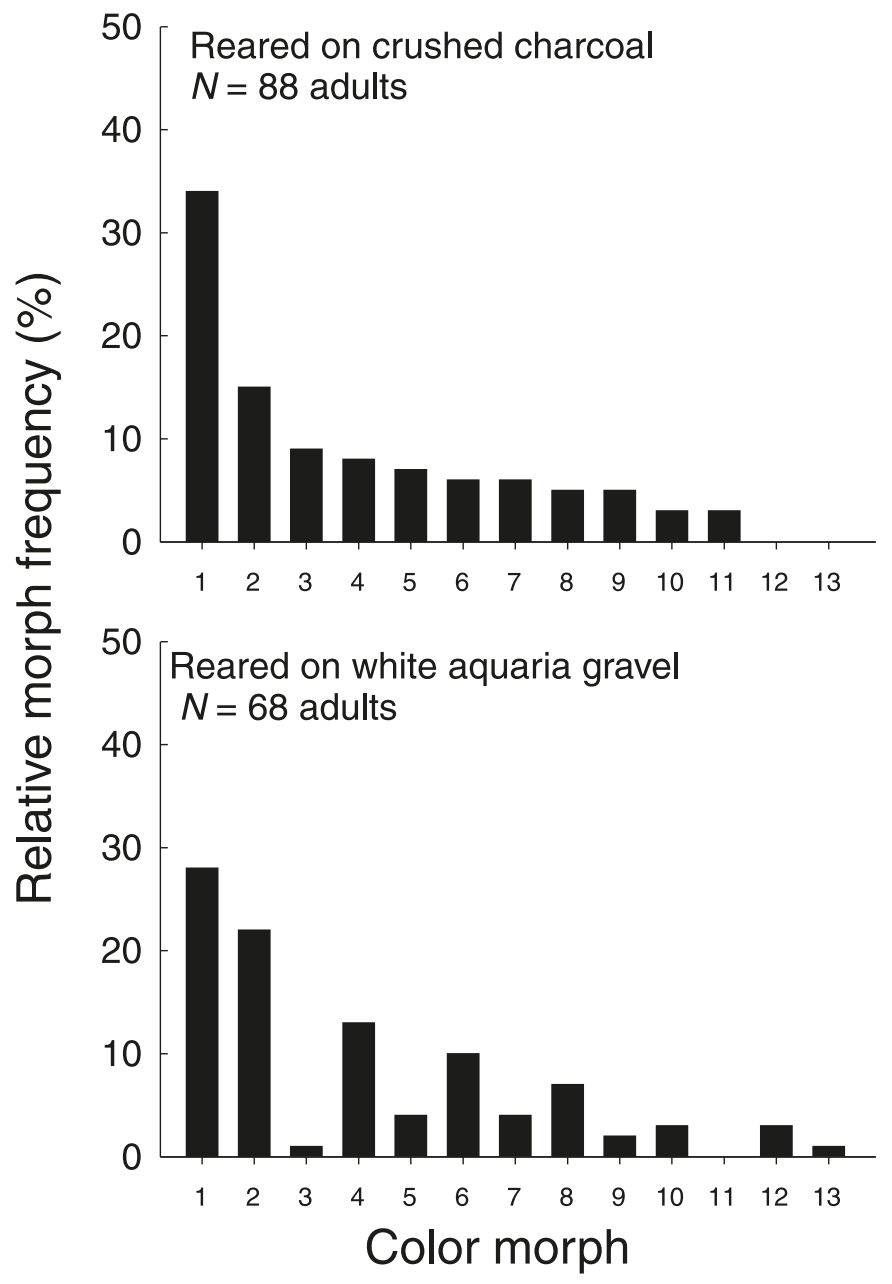

lution of color polymorphisms. Our analyses of color patterns of pygmy grasshoppers ( $T$. subulata) that had been experimentally reared in solitude on crushed charcoal versus white aquarium gravel using a split-brood design uncovered no plasticity of either color pattern or overall darkness in response to rearing substrate. Instead, we found a strong resemblance between the color patterns of mothers and those of their offspring, as well as large differences in overall darkness among families. The experimental design that we used (split brood of previously mated individuals) does not enable us to control for or estimate effects of maternal or paternal environmental conditions experienced prior to egg 
Table 1. Effects of family (mother), own color morph, rearing substrate, and own color morph by rearing substrate interaction on overall darkness of pygmy grasshopper (Tetrix subulata) coloration.

\begin{tabular}{|c|c|c|c|c|c|}
\hline Source & df & Type III SS & Mean square & $F$ & $\operatorname{Pr}>F$ \\
\hline \multicolumn{6}{|l|}{ Nymphs + adults } \\
\hline \multicolumn{6}{|c|}{$F_{[73,249]}=11.48, P<0.0001, R^{2}=0.77$} \\
\hline Mother & 48 & 14872.75 & 309.85 & 5.38 & 0.0001 \\
\hline Color morph & 13 & 12971.0 & 997.77 & 17.31 & 0.0001 \\
\hline Rearing substrate & 1 & 10.45 & 10.46 & 0.18 & 0.67 \\
\hline Morph by rearing substrate & 11 & 548.27 & 49.84 & 0.86 & 0.58 \\
\hline Error & 249 & 14349.27 & 57.62 & & \\
\hline \multicolumn{6}{|c|}{ Adults only } \\
\hline \multicolumn{6}{|c|}{$F_{[55,92]}=11.11, P<0.0001, R^{2}=0.86$} \\
\hline Mother & 33 & 7090.23 & 214.86 & 3.52 & 0.0001 \\
\hline Color morph & 12 & 5688.25 & 474.02 & 7.76 & 0.0001 \\
\hline Rearing substrate & 1 & 31.66 & 31.66 & 0.52 & 0.47 \\
\hline Morph by rearing substrate & 9 & 130.52 & 14.50 & 0.24 & 0.99 \\
\hline Error & 92 & 5623.06 & 61.12 & & \\
\hline
\end{tabular}

Note: Results from analysis of variance of data for individuals that were experimentally reared from the hatchling stage on either crushed charcoal or white aquarium gravel using a split-brood design. Results are shown for one analysis based on pooled data for nymphs and adults and one analysis based on data for adults only.

Fig. 2. Overall darkness of pygmy grasshopper (Tetrix subulata) individuals experimentally reared from the hatchling stage on either crushed charcoal or white aquarium gravel using a split-brood design. Comparison is restricted to data for 35 pairs of siblings matched with regard to color morph and representing 26 different families. Darkness was estimated as RGB value obtained from analysis of digital images and measures the average darkness of color for the red, green, and blue channels from 0 (black) to 255 (white). Figure shows means and standard deviations.

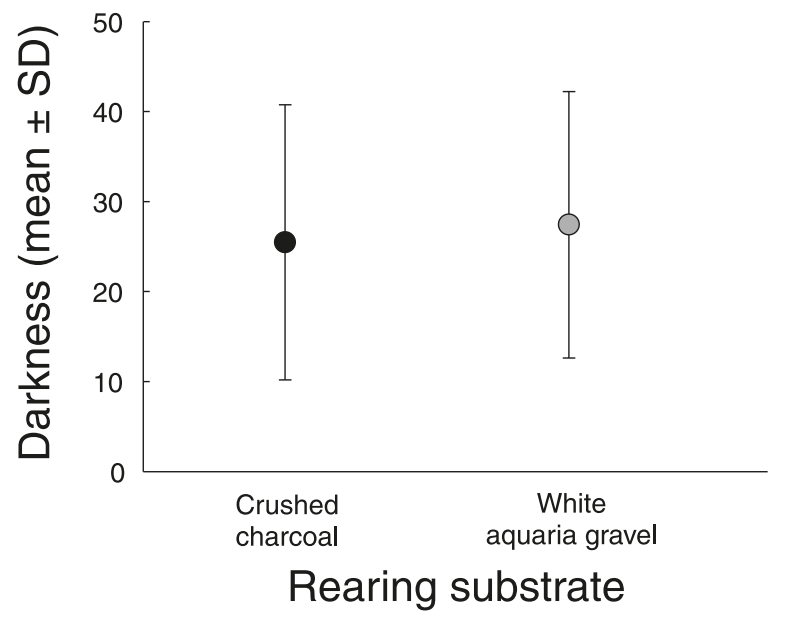

laying and during early ontogeny that may have influenced embryonic development and coloration. Our results nevertheless conform to earlier studies of T. subulata and other species of Tetrigidae, adding further support to the conclusion that pygmy grasshopper color morphs are strongly influenced by genetic cues or epigenetic maternal effects, but little (if at all) affected by posthatch developmental plasticity in response to environmental cues (Nabours 1929; Fisher 1930; Forsman et al. 2002; Ahnesjö and Forsman 2003; Karlsson et al. 2008).

Our results and conclusions are incongruent, however, with those of Hochkirch et al. (2008). These authors reared T. subulata and Tetrix ceperoi (Bolívar, 1887) on different visual backgrounds using a split-brood design but concluded that whereas the pattern itself was not influenced by plasticity, basic color showed a plastic response to the color of the rearing substrate experienced during growth, with individuals exposed to darker backgrounds developing darker color patterns. What may account for the discrepancy between our results and those of Hochkirch et al. (2008)?

First, there may be a biological explanation for the different findings. The populations included in the study by Hochkirch et al. (2008) and in our study do not share the same evolutionary history, and it is therefore possible that they now respond differently to environmental cues. But there are also several important differences in experimental design, methods, and survival of experimental animals between our study and that by Hochkirch et al. (2008) that may explain our inconsistent conclusions. In our experiment, survival of grasshoppers was high $(\sim 70 \%)$ and independent of color morph. It is therefore unlikely that differential mortality among individuals that belonged to different color morphs confounded our tests for plasticity. Instead of rearing grasshoppers together in groups, we kept them in individual cages, and differences among individuals were therefore not mistakenly interpreted as individual changes in coloration in our study. By rearing grasshoppers individually, we also avoided mistakenly interpreting a failure to capture all individuals at all sampling events as changes in relative morph frequencies. We photographed the grasshoppers and one person assigned color morph and measured overall darkness of individuals based on digital images, so we avoided problems associated with inter-observer inconsistencies in perception and changing light conditions. We arrived at a high value of measurement repeatability, both for color morph assignment (93\% for adults and $86 \%$ for nymphs) and for overall darkness (96\%), and are therefore confident that our results were not influenced to any impor- 
tant degree by intra-observer inconsistencies in morph assignment or by measurement error. That it is more difficult to reliably assign color morph of small nymphs than of adults (see Results) may also contribute to what Hochkirch et al. (2008) interpreted as reversible color changes. Finally, that we found no evidence for plasticity of coloration is not a simple consequence of low statistical power due to insufficient sample size, because our study is based on data for a much larger number of families and individuals than the study by Hochkirch et al. (2008), which yielded only 14 surviving T. subulata and 6 surviving T. ceperoi at the termination of the experiment. The problems and confounding factors discussed above were not considered and controlled for in the study by Hochkirch et al. (2008) and we therefore conclude that there are several alternative explanations to what they interpreted as plasticity. To the best of our knowledge, there exists no reliable evidence for plasticity of coloration in pygmy grasshoppers in response to environmental cues.

\section{Conclusions}

The results of the present study do not support the hypothesis that the color patterns and overall darkness of pygmy grasshoppers are influenced by developmental plasticity in response to the rearing substrate experienced during growth. Instead, our findings add to already existing evidence that color patterns of pygmy grasshoppers are under the influence of allelic variation at polymorphic loci or epigenetic maternal effects. After careful consideration of available studies, we conclude that there is no reliable evidence that the variable color patterns of $T$. subulata or any other pygmy grasshoppers are influenced by developmental plasticity in response to environmental cues. An element of plasticity would certainly add another interesting dimension to the fascinating ecological and evolutionary dynamics of color polymorphism in pygmy grasshoppers. We also do not dismiss the possibility that plasticity of coloration may have evolved in other pygmy grasshopper populations or species, or in response to other environmental cues not yet investigated, but as far as we know there is as yet no evidence to that effect. This raises the interesting question why environmentally induced variation in color patterns does not seem to occur in the tetrigid grasshoppers examined, despite being relatively common in other Orthoptera.

Our findings enable us to discriminate among the alternative explanations put forward to account for the high incidence of black and dark-colored phenotypes in pygmy grasshopper populations that inhabit recently fire-ravaged areas (Rowell 1971; Karlsson et al. 2008). The results of our experiment do not support the hypothesis that pygmy grasshoppers change coloration in response to the black visual background or some physical or chemical cues associated with burnt material. We therefore adhere to the conclusions from earlier studies that fire melanism and other microevolutionary modifications of color polymorphism in these insects are driven by a combination of selection and gene flow.

\section{Acknowledgements}

We thank C. Kindblom and M. Forsman for assistance with experimental cages and maintenance of experimental animals. Comments by L. Wennersten, F. Johansson, and two anonymous reviewers improved an earlier draft of the manuscript. The Swedish Science Council, The Swedish Research Council Formas, and the University of Kalmar (grants to A.F.) provided financial support.

\section{References}

Ahnesjö, J., and Forsman, A. 2003. Correlated evolution of colour pattern and body size in polymorphic pygmy grasshoppers, $T e$ trix undulata. J. Evol. Biol. 16(6): 1308-1318. doi:10.1046/j. 1420-9101.2003.00610.x. PMID:14640422.

Ahnesjö, J., and Forsman, A. 2006. Differential habitat selection by pygmy grasshopper color morphs; interactive effects of temperature and predator avoidance. Evol. Ecol. 20(3): 235-257. doi:10. 1007/s10682-006-6178-8.

Anstey, M.L., Rogers, S.M., Ott, S.R., Burrows, M., and Simpson, S.J. 2009. Serotonin mediates behavioral gregarization underlying swarm formation in desert locusts. Science, 323(5914): 627-630. doi:10.1126/science.1165939. PMID:19179529.

Bishop, Y.M.M., Fienberg, S.E., and Holland, P.W. 1974. Discrete multivariate analysis: theory and practice. MIT Press, Cambridge, Mass.

Caesar, S., Ahnesjö, J., and Forsman, A. 2007. Testing the role of coadapted genes versus bet-hedging for mating strategies in colour polymorphic pygmy grasshoppers. Biol. J. Linn. Soc. 90(3): 491-499. doi:10.1111/j.1095-8312.2007.00739.x.

Cott, H.B. 1940. Adaptive coloration in animals. Methuen and Co., London.

Dearn, J.M. 1990. Color pattern polymorphism. In Biology of grasshoppers. Edited by R.F. Chapman and A. Joern. John Wiley \& Sons, New York. pp. 517-549.

Fisher, R.A. 1930. The genetical theory of natural selection. Clarendon Press, Oxford, U.K.

Fisher, R.A. 1939. Selective forces in wild populations of Paratettix texanus. Ann. Eugen. 9: 109-122.

Ford, E.B. 1945. Polymorphism. Biol. Rev. Camb. Philos. Soc. 20(2): 73-88. doi:10.1111/j.1469-185X.1945.tb00315.x.

Forsman, A. 1999. Variation in thermal sensitivity of performance among colour morphs of a pygmy grasshopper. J. Evol. Biol. 12(5): 869-878. doi:10.1046/j.1420-9101.1999.00084.x.

Forsman, A. 2000. Some like it hot: Intra-population variation in behavioral thermoregulation in color-polymorphic pygmy grasshoppers. Evol. Ecol. 14(1): 25-38. doi:10.1023/ A:1011024320725.

Forsman, A., and Appelqvist, S. 1999. Experimental manipulation reveals differential effects of colour pattern on survival in male and female pygmy grasshoppers. J. Evol. Biol. 12(2): 391-401. doi:10.1046/j.1420-9101.1999.00041.x.

Forsman, A., Ringblom, K., Civantos, E., and Ahnesjö, J. 2002. Coevolution of color pattern and thermoregulatory behavior in polymorphic pygmy grasshoppers Tetrix undulata. Evolution, 56(2): $\quad 349-360 . \quad$ doi:10.1111/j.0014-3820.2002.tb01345.x. PMID:11926503.

Helfer, J.R. 1987. How to know the grasshoppers, crickets, cockroaches and their allies. Dover Publications, New York.

Hochkirch, A., Deppermann, J., and Gröning, J. 2008. Phenotypic plasticity in insects: the effects of substrate color on the coloration of two ground-hopper species. Evol. Dev. 10(3): 350-359. PMID:18460096.

Hocking, B. 1964. Fire melanism in some African grasshoppers. Evolution, 18(2): 333-335. doi:10.2307/2406407.

Karlsson, M., Caesar, S., Ahnesjö, J., and Forsman, A. 2008. Dy- 
namics of colour polymorphism in a changing environment: fire melanism and then what? Oecologia (Berl.), 154(4): 715-724. doi:10.1007/s00442-007-0876-y.

Leimar, O. 2005. The evolution of phenotypic polymorphism: randomized strategies versus evolutionary branching. Am. Nat. 165(6): 669-681. doi:10.1086/429566. PMID:15937747.

Leimar, O. 2009. Environmental and genetic cues in the evolution of phenotypic polymorphism. Evol. Ecol. 23(1): 125-135. doi:10.1007/s10682-007-9194-4.

Majerus, M.E.N. 1998. Melanism: evolution in action. Oxford University Press, New York.

Miner, B.G., Sultan, S.E., Morgan, S.G., Padilla, D.K., and Relyea, R.A. 2005. Ecological consequences of phenotypic plasticity. Trends Ecol. Evol. 20(12): 685-692. doi:10.1016/j.tree.2005.08. 002. PMID: 16701458.

Moran, N.A. 1992. The evolutionary maintenance of alternative phenotypes. Am. Nat. 139(5): 971-989. doi:10.1086/285369.

Nabours, R. 1929. The genetics of the Tettigidae (grouse locusts). Bibliogr. Genet. 5: 27-104. M. Nijhoff, The Hague.

Pigliucci, M. 2001. Phenotypic plasticity: beyond nature and nurture. John Hopkins University Press, Baltimore.

Pigliucci, M., Murren, C.J., and Schlichting, C.D. 2006. Phenotypic plasticity and evolution by genetic assimilation. J. Exp. Biol. 209(12): 2362-2367. doi:10.1242/jeb.02070. PMID:16731812.

Poulton, E.B. 1890. The colours of animals: their meaning and use, especially considered in the case of insects. D. Appleton and Company, New York.
Protas, M.E., and Patel, N.H. 2008. Evolution of coloration patterns. Annu. Rev. Cell Dev. Biol. 24(1): 425-446. doi:10.1146/ annurev.cellbio.24.110707.175302. PMID:18593352.

Roff, D.A. 1996. The evolution of threshold traits in animals. Q. Rev. Biol. 71(1): 3-35. doi:10.1086/419266.

Rowell, C.H.F. 1971. The variable coloration of the acridoid grasshoppers. In Advances in insect physiology. Vol. 8. Edited by J.W.L. Beament, J.E. Treherne, and V.B. Wigglesworth. Academic Press, London. pp. 145-198.

Ruxton, G.D., Sherratt, T.N., and Speed, M.P. 2004. Avoiding attack: the evolutionary ecology of crypsis, warning signals and mimicry. Oxford University Press, Oxford

SAS Institute Inc. 2004. SAS/STAT 9.1 user's guide. SAS Institute Inc., Cary, N.C.

Sokal, R.S., and Rohlf, F.J. 1981. Biometry. 2nd ed. Freeman, New York.

Stearns, S.C. 1989. The evolutionary significance of phenotypic plasticity: phenotypic sources of variation among organisms can be described by developmental switches and reaction norms. Bioscience, 39(7): 436-445. doi:10.2307/1311135.

Waddington, C.H. 1942. Canalization of development and the inheritance of acquired characters. Nature, 150(3811): 563-565. doi:10.1038/150563a0.

West-Eberhard, M.J. 2003. Developmental plasticity and evolution. Oxford University Press, New York. 